\title{
Long-term thiazide use and risk of low-energy fractures among persons with Alzheimer's disease-nested case-control study
}

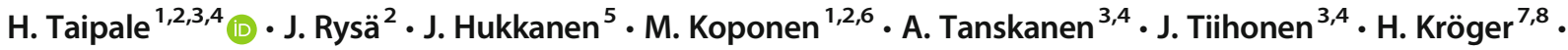 \\ S. Hartikainen ${ }^{1,2} \cdot$ A.-M. Tolppanen ${ }^{2}$
}

Received: 24 January 2019 / Accepted: 25 March 2019 /Published online: 16 April 2019

(C) The Author(s) 2019

\begin{abstract}
Summary We investigated the association between thiazide use and the risk of low-energy fractures among community dwellers with Alzheimer's disease. Longer use was associated with a decreased risk of low-energy fractures. This study extends the previous knowledge of reduced fracture risk of thiazides to persons with Alzheimer's disease.

Introduction To investigate the association between thiazide use and the risk of low-energy fractures (LEF), and hip fracture among community dwellers with Alzheimer's disease (AD). No prior study has evaluated the effect of thiazides on LEF risk of AD patients.

Methods LEF cases were identified from the MEDALZ study, including all community-dwelling persons diagnosed with AD in Finland 2005-2011. During the follow-up from AD diagnoses until the end of 2015, cases with LEF $(N=10,416)$ and hip fracture $(N=5578)$ were identified. LEF cases were matched with up to three controls without LEF, according to time since AD diagnosis, age and gender. Thiazide use identified from the Prescription register data was modeled with PRE2DUP method. Current use was defined in 0-30 days' time window before the fracture/matching date, and duration of current use was assessed. The association between thiazide exposure and LEFs was assessed with conditional logistic regression.

Results Current thiazide use was observed in $10.5 \%$ of LEF cases and $12.5 \%$ of controls. Current thiazide use was associated with a decreased risk of LEF (adjusted OR [aOR] 0.83, 95\% CI 0.77-0.88). In terms of the duration of use, no association was observed with short-term use ( $<1$ year or 1-3 years), while longer use ( $>3$ years) was associated with a reduced risk of LEF (aOR $0.77,95 \%$ CI $0.71-0.83$ ) and hip fracture (aOR $0.68,95 \%$ CI $0.60-0.78$ ).

Conclusions Our study extends the previous knowledge of reduced fracture risk of thiazides to persons with AD, a population with significantly increased background risk of fractures.
\end{abstract}

Keywords Alzheimer's disease $\cdot$ Dementia $\cdot$ Fracture $\cdot$ Hip fracture $\cdot$ Older person $\cdot$ Pharmacoepidemiology $\cdot$ Thiazide

Electronic supplementary material The online version of this article (https://doi.org/10.1007/s00198-019-04957-0) contains supplementary material, which is available to authorized users.

H. Taipale

heidi.taipale@uef.fi

1 Kuopio Research Centre of Geriatric Care, University of Eastern Finland, PO Box 1627, 70211 Kuopio, Finland

2 School of Pharmacy, University of Eastern Finland, Kuopio, Finland

3 Department of Clinical Neuroscience, Karolinska Institutet, Stockholm, Sweden

4 Department of Forensic Psychiatry, Niuvanniemi Hospital, University of Eastern Finland, Kuopio, Finland
5 Research Unit of Internal Medicine, Medical Research Center Oulu, Oulu University Hospital, University of Oulu, Oulu, Finland

6 Centre for Medicine Use and Safety, Faculty of Pharmacy and Pharmaceutical Sciences, Monash University, Parkville, VIC, Australia

7 Department of Orthopedics and Traumatology, Kuopio University Hospital, Kuopio, Finland

8 Kuopio Musculoskeletal Research Unit (KMRU), University of Eastern Finland, Kuopio, Finland 


\section{Introduction}

Thiazide diuretics were discovered over 60 years ago and they still are an efficient and cost-effective first-line choice for treating hypertension in older adults [1-3]. Thiazides may exert a beneficial effect on bone mineral density through their ability to decrease urinary calcium excretion [4]. Accordingly, the use of thiazide diuretics has been linked to increased bone density in several small epidemiological studies [5-10]. In addition, the use of thiazide diuretics has been associated with reduced risk of fractures in several studies as summarized in large meta-analyses and systematic reviews [11-13], and reported in secondary analyses of randomized controlled trials on treatment of hypertension $[14,15]$.

Association between thiazides and low-energy fractures has been studied less [16-18], and to our knowledge there are no prior studies on the association of thiazide use among persons with Alzheimer's disease, the most common form of dementia [19]. These data are important because persons with $\mathrm{AD}$ are particularly prone to falls and fractures [20,21]. Objective of our study was to investigate the association between thiazide use and risk of major/minor low-energy fracture and specifically hip fracture among community-dwelling persons with Alzheimer's disease. The impact of duration of exposure, cumulative number of exposure days, and time since discontinuation of use were assessed.

\section{Methods}

This study is a part of nationwide register-based MEDALZ (Medication use and Alzheimer's disease) data. All community-dwelling persons who received clinically verified diagnosis of AD during 2005-2011 in Finland $(N=70,718)$ were identified from the Special Reimbursement register, as described previously in detail [22]. Diagnoses of AD were based on NINCDS-ADRDA [23] and DSM-IV criteria. The diagnostic process for special reimbursement of AD medications includes computed tomography or magnetic resonance imaging scan and confirmation of the diagnosis by a neurologist or geriatrician. Data for these persons have been collected from the following nationwide registers: the Prescription Register (1995-2015; dispensed medications), the Special Reimbursement Register (1972-2015; comorbid conditions), the Hospital Discharge Register (1972-2015; hospital stays, outcome events, comorbid conditions), and socioeconomic data from the Statistics Finland. The Prescription register includes all reimbursed dispensing from pharmacies, i.e., all medications used in outpatient care but not medications used during hospital stays or over-the-counter (OTC) medications. All Finnish residents are assigned with personal identification number (PIN) which was utilized in data linkage between the registers. The linkage was conducted by the register maintainers and only de-identified data was submitted to the research team. As persons were not contacted and only deidentified data was used, no ethics committee permission was required according to Finnish legislation.

\section{Cases}

Persons hospitalized or treated in specialized outpatient care due to fractures after AD diagnoses were identified from the Hospital Discharge register data. Thus, only fractures treated in inpatient care, hospital-based emergency rooms, and hospital-based outpatient clinics were considered (i.e., primary care visits were not included). We identified persons with a major LEF (ICD-10 codes S22.0, S22.1, S32.0, S52.5, S42.2, S72.0, S72.1, S72.2) or minor LEF (S22.3, S22.4, S32.1, S32.3, S32.4, S32.5, S32.8, S42.4, S72.4, S82.5, S82.6) after AD diagnoses (Supplementary Table 1), and excluded persons who had a previous LEF fracture since 1996 (Fig. 1). Only the first major/minor LEF event after AD diagnoses was considered for each person. We further excluded persons who had potential external causes for fracture recorded at the fracture event (T, S07-S08, S17-S18, S28, S38, S47-S48, S57-S58, S67-S68, S77-S78, S87-S88, S97-S98). Cases were further categorized according to their fracture type into major and minor LEF, and from major LEF category, hip fracture (S72.0, S72.1, S72.2) was analyzed separately as it was the largest subgroup of low-energy fractures.

\section{Controls}

Fracture cases were matched with up to 3 controls without LEF by incidence density sampling (without replacement), at the date of fracture for the case which was assigned as the index date. Controls were matched according to time since $\mathrm{AD}$ diagnosis ( \pm 90 days; as proxy for duration of the disease), age ( \pm 2 years), and gender.

\section{Exposure}

Thiazides (not available OTC) were identified based on the following Anatomical Therapeutic Chemical classification (ATC) codes (including all products including thiazides as combination with other medications): thiazides alone (C03AA), thiazides in combination with potassium-sparing agents (C03EA01, C03EA02), in combination with beta blockers (C07BB02, C07BB07, C07BB12), in combination with ACE inhibitors (C09BA02, C09BA03, C09BA05), and in combination with angiotensin II antagonists (C09DA01, C09DA02, C09DA03, C09DA06, C09DA07, C09DA08, C09DX01), according to medications used in the MEDALZ data.

Medication use was modeled with PRE2DUP method [24]. The method is based on calculation of sliding averages of daily dose and according to individual purchasing behavior 
Fig. 1 Flow chart of exclusions for the study. LEF, low-energy fracture

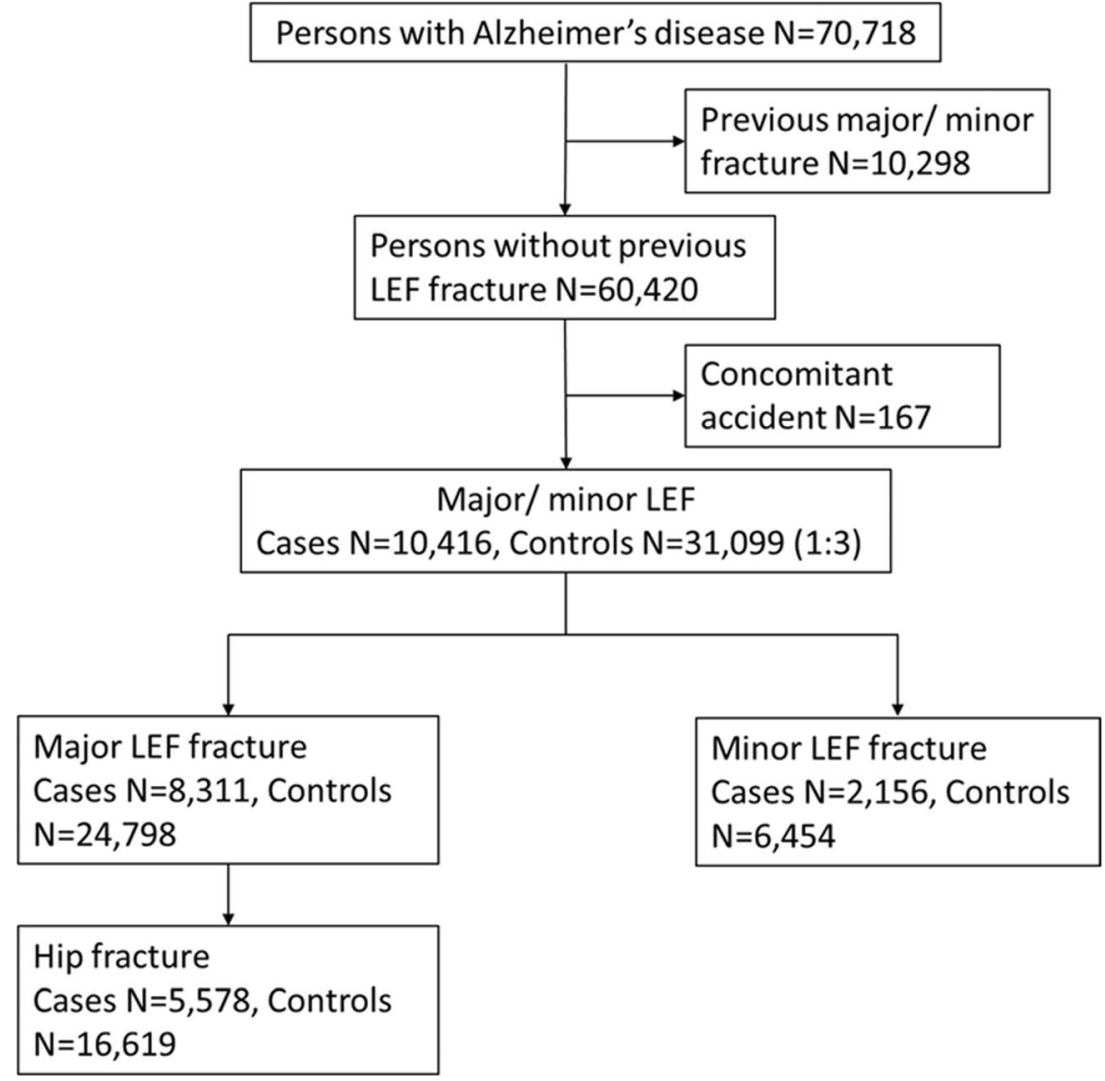

for each person and ATC code. The method considers regularity of purchases, stockpiling of medications, and possible hospital care periods when medications are provided by the health care institution. The method has been validated against expert-opinion [25] and self-reported medication use in interview [26]. Agreement between PRE2DUP modeled use and interview for diuretics was very good (Cohen's kappa 0.89, 95\% CI 0.85-0.93). Post processing feature of PRE2DUP was utilized in combining drug use periods of each specific ATC code including a thiazide into duration of "any thiazide" use. This means that the drug use periods were combined as a one continuous period if there was no break in the use. The drug use periods define when thiazide use started and ended for each person and duration of use.

Current use was defined in 0-30 day time window before the index date (Supplementary Fig. 1A). For current users, we defined the duration of use for the drug use period that was ongoing at the time window. The ever use of thiazides was defined as a use period occurring ever since 1995 but before the index date (referred as observation period, Supplementary Fig. 1B). For the ever users, cumulative duration of use was defined by summing up durations of all drug use periods during the observation period for each person. Duration of use was categorized as $<1,1-3,3-5$ and $\geq 5$ years. Time since discontinuation of thiazide use was defined as time since the end date of the last thiazide use period before the index date.
Time since discontinuation of use was categorized as $0-30$, $31-365$, and $>365$ days.

\section{Comorbidities}

Factors associated with thiazide use and risk of low-energy fractures [21, 27, 28] were considered as covariates and derived from the registers. All comorbidities were measured before the index date. Comorbidities from Special Reimbursement register were considered since 1972, and most comorbidities from the Hospital Discharge register since 1996 when ICD-10 codes were introduced and operations since 1994 when NOMESCO codes were introduced. History of stroke and substance abuse was defined since 1972 with corresponding ICD-8 and ICD-9 codes. Medication use was measured during 6 months before the index date except for bisphosphonate use as a marker for osteoporosis which was considered since 1995. Exact definitions are provided in the Supplementary Table 2. Comorbid conditions that were strongly correlated with each other were excluded from the adjusted models. Thus, the final adjusted models included socioeconomic status, number of hospital days during observation period (as a proxy for overall comorbidity), diabetes, rheumatoid arthritis and other connective tissue diseases, chronic heart failure, atrial fibrillation, epilepsy, asthma/COPD, substance abuse, active cancer, 
osteoporosis, glaucoma, previous stroke, prosthetic replacement of hip joint or knee joint, renal failure, and the use of following medications ( 180 days before the index date): antipsychotics, antidepressants, benzodiazepines and related drugs, antiepileptics, acetylcholinesterase inhibitors, memantine, opioids, non-steroidal anti-inflammatory drugs, paracetamol, oral glucocorticoids, inhaled glucocorticoids, proton-pump inhibitors, hormone replacement therapy, loop diuretics, beta blockers, calcium channel blockers, and reninangiotensin system inhibitors.

\section{Statistical analyses}

The association between thiazide exposure and fractures was assessed with conditional logistic regression models, which accounts for the matched design. Current thiazide use (during 0-30 days before the index date) was compared with no thiazide use during the time window and categorized according to continuous duration of current use $(<1,1-<3,3-<5$, and $\geq 5$ years). The ever use and cumulative duration of thiazide use $(<1,1-<3,3-<5$, and $\geq 5$ years) were compared with the never use of thiazides since 1995 until the index date. Time since discontinuation of use $(0-30,31-365$, and $>365$ days $)$ and cumulative duration of use $(<1,1-<3,3-<5$, and $\geq 5$ years $)$ were compared with never use of thiazides.

Separate analyses were conducted for major and minor LEFs, and hip fractures as outcome events. All analyses were performed using SAS statistical software, version 9.4 (SAS Institute, Inc., Cary, NC). The results are reported as unadjusted and adjusted odds ratios (OR) with $95 \%$ confidence intervals $(\mathrm{CI})$.

\section{Results}

Cases with low-energy fracture were on average 84 years old and $76 \%$ were women (Table 1). After diagnoses of AD, median time to the first LEF was 2.6 years. Compared with controls, cases were more likely to have comorbidities such as rheumatoid arthritis, atrial fibrillation, epilepsy, osteoporosis, history of stroke, and prosthetic replacement of hip or knee joint. They also used more often psychotropics and analgesics than controls whereas beta blocker and calcium channel blocker use was similar and renin-angiotensin system inhibitor use and hormone-replacement therapy were less frequent than among controls. Comparison between hip fracture cases and controls resulted in similar findings (Supplementary Table 3).

The majority of low-energy fractures were major LEFs $(80 \%, N=8311)$. Of major LEFs, hip fractures were the most common fracture type ( $N=5578,67 \%$ of major LEFs and $54 \%$ of all low-energy fractures).

Current thiazide use was observed in $10.5 \%$ of LEF cases and $12.5 \%$ of their controls (Table 2). Current thiazide use was associated with a decreased risk of LEF (adjusted OR [aOR] $0.83,95 \%$ CI 0.77-0.88). When current use was assessed according to the duration of use, short-term $(<1$ year or $1-$ 3 years) use was not associated with LEFs whereas longer use was associated with a reduced risk of LEFs $(3-5$ years aOR $0.70,95 \%$ CI $0.61-0.86 ; \geq 5$ years aOR $0.78,95 \%$ CI $0.71-$ $0.86 ;>3$ years aOR $0.77,95 \%$ CI $0.71-0.83$ ). The ever use of thiazides was not associated with LEF. However, cumulative duration of use for over 5 years was associated with a reduced risk of LEF also in the ever users (aOR 0.90, 95\% CI 0.85 0.95 ). When assessed according to time since discontinuation of thiazide use, only the use until the fracture event or discontinuation within 30 days before the index date was associated with a reduced risk (aOR $0.83,95 \%$ CI $0.78-0.89$ ) whereas the more distant use (30-365 or $>365$ days since discontinuation) was not associated with the risk. When the cumulative duration of use was categorized according to time since discontinuation ( $\leq 30$ vs. $>30$ days), only cumulative use for $\geq$ 5 years which was discontinued $\leq 30$ days ago was associated with reduced risk of LEF (aOR 0.79, 95\% CI 0.73-0.85).

Findings on subcategories major LEF (Supplementary Table 4) and minor LEF (Supplementary Table 5) were similar, except that low number of minor LEFs resulted in non-significant associations. Associations between thiazide use and hip fracture were similar although somewhat stronger than for LEFs (Table 3). Current thiazide use was associated with a reduced risk of hip fracture (aOR 0.77 , 95\% CI 0.69-0.85), and the association was seen with longer durations of use (3-5 years aOR $0.67,95 \%$ CI $0.51-$ $0.87 ; \geq 5$ years of use aOR $0.69,95 \%$ CI $0.59-0.79 ;>$ 3 years use $0.68,95 \%$ CI $0.60-0.78$ ).

\section{Discussion}

Current thiazide use was associated with a decreased risk of LEFs. The association was observed only for longer duration of use ( $>3$ years) and not evident if the use was discontinued over 1 month before the index date. The association was similar for hip fractures which were the most common category of fractures, and also for all subcategories although the confidence intervals were wider for minor LEFs due to smaller sample size.

As the use of diuretics has been associated with an increased risk of falls [29], the decreased risk of LEFs associated with thiazide use is somewhat surprising in this old and vulnerable patient group which has an increased baseline risk for falls and fractures [20,21]. Persons with advanced age and dementia are underrepresented in clinical trials in general, and 
Table 1 Comparison of lowenergy fracture cases $(N=$ $10,416)$ and controls $(N=31,099)$

\begin{tabular}{|c|c|c|c|c|c|}
\hline & Control $N$ & Case $N$ & $\begin{array}{l}\text { Control } \\
\%\end{array}$ & $\begin{array}{l}\text { Case } \\
\%\end{array}$ & $p$ value \\
\hline Females & 23,483 & 7864 & 75.5 & 75.5 & 0.9816 \\
\hline Mean age, SD & $83.7(6.1)$ & $83.9(6.3)$ & & & 0.0540 \\
\hline $\begin{array}{l}\text { Time since AD diagnoses, median } \\
\text { (IQR) }\end{array}$ & $\begin{array}{r}934 \\
(445-1540)\end{array}$ & $\begin{array}{r}934 \\
(445-1540)\end{array}$ & & & 0.5071 \\
\hline Socioeconomic position & & & & & 0.0464 \\
\hline High & 10,737 & 3468 & 34.5 & 33.3 & \\
\hline Medium & 18,110 & 6153 & 58.2 & 59.1 & \\
\hline Low & 1908 & 657 & 6.1 & 6.3 & \\
\hline Unknown & 344 & 138 & 1.1 & 1.3 & \\
\hline \multicolumn{2}{|c|}{ Hospital days during the observation period } & & & & $<.0001$ \\
\hline 0 & 1366 & 371 & 4.4 & 3.6 & \\
\hline $1-90$ & 20,230 & 6687 & 65.1 & 64.2 & \\
\hline$>90$ & 9503 & 3358 & 30.6 & 32.2 & \\
\hline \multicolumn{6}{|l|}{ Comorbidities } \\
\hline Diabetes & 6016 & 1941 & 19.3 & 18.6 & 0.1111 \\
\hline Rheumatoid arthritis & 1400 & 562 & 4.5 & 5.4 & 0.0002 \\
\hline Chronic heart failure & 5144 & 1849 & 16.5 & 17.8 & 0.0043 \\
\hline Atrial fibrillation & 5444 & 2134 & 17.5 & 20.5 & $<.0001$ \\
\hline Epilepsy & 635 & 305 & 2.0 & 2.9 & $<.0001$ \\
\hline Asthma/COPD & 3171 & 1166 & 10.2 & 11.2 & 0.004 \\
\hline History of substance abuse & 780 & 321 & 2.5 & 3.1 & 0.0016 \\
\hline Active cancer & 1467 & 654 & 4.7 & 6.3 & $<.0001$ \\
\hline Osteoporosis & 4832 & 1918 & 15.5 & 18.4 & $<.0001$ \\
\hline Glaucoma & 3274 & 1045 & 10.5 & 10.0 & 0.1521 \\
\hline Previous stroke & 3628 & 1364 & 11.7 & 13.1 & 0.0001 \\
\hline $\begin{array}{l}\text { Prosthetic replacement of hip joint } \\
\text { or knee joint }\end{array}$ & 3790 & 3391 & 12.2 & 32.6 & $<.0001$ \\
\hline Renal failure & 377 & 166 & 1.2 & 1.6 & 0.003 \\
\hline \multicolumn{6}{|l|}{$\begin{array}{l}\text { Medication use during } 180 \text { days } \\
\text { before the index date }\end{array}$} \\
\hline Antipsychotics & 6947 & 2984 & 22.1 & 25.4 & $<.0001$ \\
\hline Antidepressants & 8332 & 3718 & 25.5 & 31.7 & $<.0001$ \\
\hline Benzodiazepines and related drugs & 7545 & 3314 & 24.4 & 28.3 & $<.0001$ \\
\hline Antiepileptics & 1771 & 859 & 5.7 & 7.3 & $<.0001$ \\
\hline Acetylcholinesterase inhibitors & 19,732 & 7628 & 63.6 & 65.0 & 0.0069 \\
\hline Memantine & 11,096 & 4460 & 35.6 & 38.0 & $<.0001$ \\
\hline Opioids & 2735 & 1404 & 8.5 & 12.0 & $<.0001$ \\
\hline NSAIDs & 2548 & 1151 & 8.3 & 9.8 & $<.0001$ \\
\hline Paracetamol & 9277 & 4154 & 28.3 & 35.4 & $<.0001$ \\
\hline Oral glucocorticoids & 1483 & 712 & 4.7 & 6.1 & $<.0001$ \\
\hline Inhaled glucocorticoids & 918 & 382 & 3.1 & 3.3 & 0.4223 \\
\hline PPIs & 6503 & 2790 & 20.6 & 23.8 & $<.0001$ \\
\hline Hormone replacement therapy & 1582 & 529 & 5.2 & 4.5 & 0.0033 \\
\hline Loop diuretics & 7699 & 3098 & 23.9 & 26.4 & $<.0001$ \\
\hline Beta blockers & 13,612 & 5234 & 43.6 & 44.6 & 0.0632 \\
\hline Calcium channel blockers & 6381 & 2401 & 20.4 & 20.5 & 0.9393 \\
\hline Renin-angiotensin system inhibitors & 11,499 & 4207 & 37.2 & 35.9 & 0.0166 \\
\hline
\end{tabular}

$C O P D$, chronic obstructive pulmonary disease; $N S A I D$, non-steroidal anti-inflammatory drugs; $P P I$, proton pump inhibitor 
Table 2 Associations between low-energy fractures (both minor and major) and current thiazide use, duration of current use, duration of cumulative use, and time since discontinuation of use

\begin{tabular}{|c|c|c|c|c|c|c|c|c|c|c|}
\hline & Control $N$ & Case $N$ & Control \% & Case $\%$ & Unadjusted OR & Lower CI & Upper CI & Adjusted $\mathrm{OR}^{\mathrm{a}}$ & Lower CI & Upper CI \\
\hline Current use & 3881 & 1097 & 12.5 & 10.5 & 0.83 & 0.78 & 0.88 & 0.83 & 0.77 & 0.88 \\
\hline \multicolumn{11}{|l|}{ Duration of current use } \\
\hline$<1$ year & 588 & 179 & 1.9 & 1.7 & 0.89 & 0.77 & 1.03 & 0.91 & 0.78 & 1.06 \\
\hline $1-3$ years & 825 & 259 & 2.7 & 2.5 & 0.92 & 0.82 & 1.03 & 0.94 & 0.83 & 1.07 \\
\hline $3-5$ years & 579 & 146 & 1.9 & 1.4 & 0.74 & 0.63 & 0.87 & 0.70 & 0.61 & 0.86 \\
\hline$\geq 5$ years & 1890 & 511 & 6.1 & 4.9 & 0.79 & 0.73 & 0.86 & 0.78 & 0.71 & 0.86 \\
\hline \multicolumn{11}{|l|}{ Cumulative use } \\
\hline Ever use & 12,964 & 4298 & 41.7 & 41.3 & 0.98 & 0.95 & 1.02 & 0.96 & 0.92 & 1.00 \\
\hline$<1$ year & 2734 & 959 & 8.8 & 9.2 & 1.04 & 0.97 & 1.11 & 1.00 & 0.93 & 1.07 \\
\hline $1-3$ years & 2166 & 740 & 7.0 & 7.1 & 1.01 & 0.94 & 1.09 & 1.00 & 0.93 & 1.09 \\
\hline $3-5$ years & 1662 & 586 & 5.3 & 5.6 & 1.05 & 0.97 & 1.13 & 1.03 & 0.95 & 1.13 \\
\hline$\geq 5$ years & 6402 & 2013 & 20.6 & 19.3 & 0.93 & 0.89 & 0.98 & 0.90 & 0.85 & 0.95 \\
\hline \multicolumn{11}{|c|}{ Time since discontinuation of use } \\
\hline $0-30$ days & 3882 & 1095 & 12.5 & 10.5 & 0.84 & 0.79 & 0.89 & 0.83 & 0.78 & 0.89 \\
\hline 31-365 days & 1270 & 499 & 4.1 & 4.8 & 1.17 & 1.07 & 1.28 & 1.15 & 1.04 & 1.26 \\
\hline$>365$ days & 7812 & 2695 & 25.1 & 25.9 & 1.03 & 0.98 & 1.07 & 0.98 & 0.94 & 1.03 \\
\hline \multirow{2}{*}{\multicolumn{11}{|c|}{$\begin{array}{l}\text { Time since discontinuation of use and cumulative duration of use } \\
\leq 30 \text { days since discontinuation }\end{array}$}} \\
\hline & & & & & & & & & & \\
\hline Duration < 1 year & 280 & 82 & 0.9 & 0.8 & 0.87 & 0.70 & 1.08 & 0.89 & 0.71 & 1.11 \\
\hline Duration $1-3$ years & 509 & 159 & 1.6 & 1.5 & 0.93 & 0.80 & 1.08 & 0.93 & 0.78 & 1.06 \\
\hline Duration $3-5$ years & 500 & 147 & 1.6 & 1.4 & 0.87 & 0.75 & 1.02 & 0.90 & 0.76 & 1.06 \\
\hline Duration $\geq 5$ years & 2593 & 707 & 8.3 & 6.8 & 0.81 & 0.75 & 0.87 & 0.79 & 0.73 & 0.85 \\
\hline \multicolumn{11}{|c|}{$>30$ days since discontinuation } \\
\hline Duration < 1 year & 2454 & 873 & 7.9 & 8.4 & 1.06 & 0.99 & 1.13 & 1.01 & 0.94 & 1.09 \\
\hline Duration $1-3$ years & 1657 & 580 & 5.3 & 5.6 & 1.04 & 0.96 & 1.13 & 1.03 & 0.94 & 1.12 \\
\hline Duration $3-5$ years & 1162 & 438 & 3.7 & 4.2 & 1.12 & 1.03 & 1.23 & 1.09 & 0.99 & 1.21 \\
\hline Duration $\geq 5$ years & 3809 & 1303 & 12.3 & 12.5 & 1.02 & 0.96 & 1.09 & 0.97 & 0.91 & 1.03 \\
\hline
\end{tabular}

${ }^{\text {a }}$ Adjusted for socioeconomic position, number of hospital days during observation period, diabetes, rheumatoid arthritis, chronic heart failure, atrial fibrillation, epilepsy, asthma/COPD, history of substance abuse, active cancer, osteoporosis, glaucoma, previous stroke, prosthetic replacement of hip joint or knee joint, renal failure, medication use (180 days before the index date): antipsychotics, antidepressants, benzodiazepines and related drugs, antiepileptics, acetylcholinesterase inhibitors, memantine, opioids, non-steroidal anti-inflammatory drugs, paracetamol, oral glucocorticoids, inhaled glucocorticoids, proton pump inhibitors, hormone replacement therapy, loop diuretics, beta blockers, calcium channel blockers, and renin-angiotensin system inhibitors

The number of cases $N=10,416$ and controls $N=31,099$

also in trials of thiazides as pointed out by recent metaanalyses on effectiveness and safety of thiazide use in treatment of hypertension in older adults [12]. In previous studies, diuretic use has been associated with an increased risk of falling although the risk was more evident for loop diuretics than for thiazides [30]. The increased risk of falling during diuretic use may be related to common adverse effects of antihypertensives, including dizziness, hyponatremia and postural hypotension [31]. The protective association between thiazide use and LEFs, especially with the long-term use observed in our study, may be explained by the previous findings that the use of thiazide diuretics increases bone mineral density in postmenopausal women and older men in randomized clinical trials $[32,33]$. Alternatively, it is possible that thiazide use was discontinued if there were indications of increased risk of falls or fractures and thus, the decreased risk of LEF in long-term thiazide users may partially be explained by selection (i.e., users may be those who tolerate thiazide effects and thus, continue thiazide use).

Our finding of the reduced risk of fractures associated with thiazide use is in good agreement with secondary analyses of randomized clinical trials. Indapamide vs. placebo reduced the risk of fractures in hypertensive patients with $\geq 80$ years of age [14], and patients randomized to chlorthalidone vs. amlodipine or lisinopril had a lower risk of hip and pelvic fractures (age $\geq 55$ years) [15]. However, in those two studies 
Table 3 Associations between hip fracture and current thiazide use, duration of current use, duration of cumulative use, and time since discontinuation of use

\begin{tabular}{|c|c|c|c|c|c|c|c|c|c|c|}
\hline & Control $N$ & Case $N$ & Control \% & Case $\%$ & Unadjusted OR & Lower CI & Upper CI & Adjusted $\mathrm{OR}^{\mathrm{a}}$ & Lower CI & Upper CI \\
\hline Current use & 2015 & 534 & 12.1 & 9.6 & 0.77 & 0.70 & 0.84 & 0.77 & 0.69 & 0.85 \\
\hline \multicolumn{11}{|l|}{ Duration of current use } \\
\hline$<1$ year & 280 & 79 & 1.7 & 1.4 & 1.03 & 0.94 & 1.13 & 0.88 & 0.69 & 1.12 \\
\hline $1-3$ years & 424 & 137 & 2.6 & 2.5 & 0.99 & 0.89 & 1.10 & 0.96 & 0.80 & 1.15 \\
\hline $3-5$ years & 300 & 77 & 1.8 & 1.4 & 1.05 & 0.94 & 1.17 & 0.67 & 0.51 & 0.87 \\
\hline$\geq 5$ years & 1011 & 240 & 6.1 & 4.3 & 0.91 & 0.85 & 0.97 & 0.69 & 0.59 & 0.79 \\
\hline \multicolumn{11}{|l|}{ Cumulative use } \\
\hline Ever use & 6911 & 2273 & 41.6 & 40.8 & 0.97 & 0.92 & 1.02 & 0.95 & 0.89 & 1.01 \\
\hline$<1$ year & 1427 & 504 & 8.6 & 9.0 & 1.03 & 0.94 & 1.13 & 1.00 & 0.90 & 1.11 \\
\hline $1-3$ years & 1169 & 393 & 7.0 & 7.1 & 0.99 & 0.89 & 1.10 & 1.02 & 0.90 & 1.15 \\
\hline $3-5$ years & 905 & 322 & 5.5 & 5.8 & 1.05 & 0.94 & 1.17 & 1.06 & 0.93 & 1.21 \\
\hline$\geq 5$ years & 3410 & 1054 & 20.5 & 18.9 & 0.91 & 0.85 & 0.97 & 0.87 & 0.80 & 0.95 \\
\hline \multicolumn{11}{|c|}{ Time since discontinuation of use } \\
\hline $0-30$ days & 2015 & 533 & 12.1 & 9.6 & 0.78 & 0.71 & 0.85 & 0.77 & 0.70 & 0.86 \\
\hline 31-365 days & 645 & 271 & 3.9 & 4.9 & 1.24 & 1.09 & 1.40 & 1.25 & 1.08 & 1.45 \\
\hline$>365$ days & 4251 & 1462 & 25.6 & 26.2 & 1.02 & 0.96 & 1.08 & 0.98 & 0.91 & 1.05 \\
\hline \multirow{2}{*}{\multicolumn{11}{|c|}{$\begin{array}{l}\text { Time since discontinuation of use and cumulative duration of use } \\
\leq 30 \text { days since discontinuation }\end{array}$}} \\
\hline & & & & & & & & & & \\
\hline Duration < 1 year & 140 & 35 & 0.8 & 0.6 & 0.73 & 0.53 & 1.02 & 0.82 & 0.60 & 1.14 \\
\hline Duration $1-3$ years & 249 & 80 & 1.5 & 1.4 & 0.95 & 0.76 & 1.18 & 0.98 & 0.76 & 1.28 \\
\hline Duration $3-5$ years & 257 & 80 & 1.6 & 1.4 & 0.92 & 0.74 & 1.14 & 0.92 & 0.71 & 1.19 \\
\hline Duration $\geq 5$ years & 1369 & 338 & 8.2 & 6.1 & 0.73 & 0.65 & 0.81 & 0.70 & 0.62 & 0.80 \\
\hline \multicolumn{11}{|c|}{$>30$ days since discontinuation } \\
\hline Duration < 1 year & 1287 & 465 & 7.7 & 8.3 & 1.07 & 0.97 & 1.17 & 1.01 & 0.91 & 1.13 \\
\hline Duration $1-3$ years & 920 & 313 & 5.5 & 5.6 & 1.00 & 0.90 & 1.12 & 1.02 & 0.89 & 1.16 \\
\hline Duration 3-5 years & 648 & 242 & 3.9 & 4.3 & 1.10 & 0.97 & 1.25 & 1.11 & 0.95 & 1.30 \\
\hline Duration $\geq 5$ years & 2041 & 713 & 12.3 & 12.8 & 1.03 & 0.96 & 1.12 & 0.98 & 0.89 & 1.08 \\
\hline
\end{tabular}

${ }^{a}$ Adjusted for socioeconomic position, number of hospital days during observation period, diabetes, rheumatoid arthritis, chronic heart failure, atrial fibrillation, epilepsy, asthma/COPD, history of substance abuse, active cancer, osteoporosis, glaucoma, previous stroke, prosthetic replacement of hip joint or knee joint, renal failure, medication use (180 days before the index date): antipsychotics, antidepressants, benzodiazepines and related drugs, antiepileptics, acetylcholinesterase inhibitors, memantine, opioids, non-steroidal anti-inflammatory drugs, paracetamol, oral glucocorticoids, inhaled glucocorticoids, proton pump inhibitors, hormone replacement therapy, loop diuretics, beta blockers, calcium channel blockers, and renin-angiotensin system inhibitors

The number of cases $N=5578$ and controls $N=16,619$

patients with dementia were excluded or their proportion was not reported, respectively. There are no prior studies on thiazide use among persons with $\mathrm{AD}$ or other form of dementia that investigated fracture risk as a primary outcome. Thus, despite the reduced risk of LEF in our study, thiazides cannot be recommended as a preventative therapy for fractures. Nevertheless, thiazide diuretics should be considered when choosing the hypertension treatment or when decreasing the number of used antihypertensives among older persons. However, orthostatic hypotension and other risk factors have to be assessed and considered carefully.

A major strength of this study was a large, nationwide cohort of community-dwelling persons with Alzheimer's disease. Thus, the results are generalizable to communitydwelling persons with AD. The analyses were restricted to the first fractures after AD diagnoses as the reliability of incident fractures is well demonstrated, especially for hip fractures in the Finnish Hospital Discharge register [34]. However, the outcome measure was limited to fractures treated in hospitals and hospital-based clinics, and thus, does not cover fractures treated in primary healthcare. The observation period for thiazide use was at least 10 years for all participants representing truly long-term use. Thiazide use was identified from all combinations of cardiovascular drugs to gather total exposure to this drug class, and modeled with PRE2DUP method which results 
in highly reliable estimates of exposure [25, 26, 35]. Although the Prescription register data is restricted to reimbursed drugs only, thiazides had reimbursement status throughout the follow-up with very few exceptions.

A nested case-control approach was chosen to be able to observe long-term drug use patterns, both current use and cumulative exposure over time. Controls without LEF were matched with LEF cases by age, gender, and time since $\mathrm{AD}$ diagnoses as these were judged to be the major factors predicting risk of falls and fractures. As we lack data on the severity of $\mathrm{AD}$ and cognitive decline, time since AD diagnoses was considered as a proxy for the progression of the disease. Because both cases and controls were drawn from a well-defined source population (i.e., all community-dwellers with $\mathrm{AD}$ diagnosis) and controls were selected by incidence density sampling, the OR, apart from random error, is the same as RR in the source population [36]. The analyses were adjusted for comorbid conditions, socioeconomic status, and other drug use which have been associated with risk of falling in previous studies. However, residual confounding may still exist as we lacked data on important predictors of falling, for example nutritional status, alcohol consumption, and balance and mobility measures. In this aged population, these factors are assumed to be captured at least partly by the comorbid conditions used as covariates.

\section{Conclusions}

Our finding of a lower risk of low-energy fractures in longterm thiazide users extends the knowledge of reduced fracture risk to older persons with Alzheimer's disease. This finding may have implications for the choice of antihypertensive medications in this vulnerable patient group with an increased background risk for falls and fractures due to dementia disorder.

Acknowledgements Open access funding provided by University of Eastern Finland (UEF) including Kuopio University Hospital.

\section{Compliance with ethical standards}

Conflicts of interest HT, JT, and AT have participated in research projects funded by Janssen and Eli Lilly with grants paid to the institution where they were employed. JT has received personal fees from the Finnish Medicines Agency (Fimea), European Medicines Agency (EMA), Eli Lilly, Janssen-Cilag, Lundbeck, and Otsuka; and has received grants from the Stanley Foundation and Sigrid Jusélius Foundation. SH has received fees from Swedish Research Council. Other authors declare no conflicts of interest.

Ethics approval and consent to participate Data were retrieved from the registers by the register maintainers and de-identified register data were submitted to the research team. Participants were not contacted in any way. According to Finnish legislation, no ethics committee approval is required in these circumstances.

Open Access This article is distributed under the terms of the Creative Commons Attribution-NonCommercial 4.0 International License (http:// creativecommons.org/licenses/by-nc/4.0/), which permits any noncommercial use, distribution, and reproduction in any medium, provided you give appropriate credit to the original author(s) and the source, provide a link to the Creative Commons license, and indicate if changes were made.

\section{References}

1. The ALLHAT Officers (2002) Major outcomes in high-risk hypertensive patients randomized to or calcium channel blocker vs diuretic. J Am Med Assoc 288:2981-2997

2. Program E (1991) Prevention of stroke by antihypertensive drug treatment in older persons with isolated systolic hypertension. JAMA 265:3255

3. Williams B, Mancia G, Spiering W et al (2018) 2018 ESC/ESH guidelines for the management of arterial hypertension. Eur $\mathrm{J}$ Heart 39:3021-3104

4. Lamberg BA, Kuhlback B (1959) Effect of chlorothiazide and hydrochlorothiazide on the excretion of calcium in urine. Scand J Clin Lab Invest 11:351-357

5. Sigurdsson G, Franzson L (2001) Increased bone mineral density in a population-based group of 70-year-old women on thiazide diuretics, independent of parathyroid hormone levels. J Intern Med 250:51-56

6. Hill DD, Cauley JA, Bunker CH, Baker CE, Patrick AL, Beckles GLA, Wheeler VW, Zmuda JM (2008) Correlates of bone mineral density among postmenopausal women of African Caribbean ancestry: Tobago women's health study. Bone 43:156-161

7. Ooms M, Lips P, Van Lingen A, Valkenburg H (1993) Determinants of bone mineral density and risk factors for osteoporosis in healthy elderly women. J Bone Miner Res 8:669-675

8. Glynn N, Meilahn E, Charron M, Anderson S, Kuller L, Cauley J (1995) Determinants of bone mineral density in older men. J Bone Miner Res 10:1769-1777

9. Lim LS, Fink HA, Kuskowski MA, Cauley JA, Ensrud KE, Group $\mathrm{F}$ the OF in M (MrOS) study (2005) Diuretic use and bone mineral density in older USA men: the osteoporotic fractures in men (MrOS) study. Age Ageing 34:501-504

10. Lau EMC, Leung PC, Kwok T, Woo J, Lynn H, Orwoll E, Cummings S, Cauley J (2006) The determinants of bone mineral density in Chinese men - results from Mr. Os (Hong Kong), the first cohort study on osteoporosis in Asian men. Osteoporos Int 17:297303

11. Xiao X, Xu Y, Wu Q (2018) Thiazide diuretic usage and risk of fracture: a meta-analysis of cohort studies. Osteoporos Int 29:15151524

12. Sommerauer C, Kaushik N, Woodham A, Renom-Guiteras A, Martinez YV, Reeves D, Kunnamo I, al Qur'an T, Hübner S, Sönnichsen A (2017) Thiazides in the management of hypertension in older adults - a systematic review. BMC Geriatr 17:228

13. Aung K, Htay T (2011) Thiazide diuretics and the risk of hip fracture. Cochrane Database Syst Rev 5:CD005185

14. Peters R, Beckett N, Burch L, de Vernejoul MC, Liu L, Duggan J, Swift C, Gil-Extremera B, Fletcher A, Bulpitt C (2010) The effect of treatment based on a diuretic (indapamide) \pm ACE inhibitor (perindopril) on fractures in the hypertension in the very elderly trial (HYVET). Age Ageing 39:609-616

15. Puttnam R, Davis BR, Pressel SL, Whelton PK, Cushman WC, Louis GT, Margolis KL, Oparil S, Williamson J, Ghosh A, 
Einhorn PT, Barzilay JI, for the Antihypertensive and LipidLowering Treatment to Prevent Heart Attack Trial (ALLHAT) Collaborative Research Group (2017) Association of 3 different antihypertensive medications with hip and pelvic fracture risk in older adults secondary analysis of a randomized clinical trial. JAMA Intern Med 177:67-76

16. Schoofs MWCJ, Van Der Klift M, Hofman A et al (2003) Thiazide diuretics and the risk for hip fracture. Ann Intern Med 139:476-482

17. Paik JM, Rosen HN, Gordon CM, Curhan GC (2016) Diuretic use and risk of vertebral fracture in women. Am J Med 129:1299-1306

18. De Vecchis R, Ariano C, Di Biase G, Noutsias M (2017) Thiazides and osteoporotic spinal fractures: a suspected linkage investigated by means of a two-center, case-control study. J Clin Med Res 9: 943-949

19. Fargo K (2014) Alzheimer's association report: 2014 Alzheimers disease facts and figures. Alzheimers Dement 10:e47-e92

20. Friedman SM, Mendelson DA (2014) Epidemiology of fragility fractures. Clin Geriatr Med 30:175-181

21. Tolppanen A-M, Taipale H, Tanskanen A, Tiihonen J, Hartikainen S (2016) Comparison of predictors of hip fracture and mortality after hip fracture in community-dwellers with and without Alzheimer's disease - exposure-matched cohort study. BMC Geriatr 16:204

22. Tolppanen A-M, Taipale H, Koponen M, Lavikainen P, Tanskanen A, Tiihonen J, Hartikainen S (2016) Cohort profile: the Finnish medication and Alzheimer's disease (MEDALZ) study. BMJ Open 6:e012100

23. McKhann G, Drachman D, Folstein M, Katzman R, Price D, Stadlan EM (1984) Clinical diagnosis of Alzheimer's disease: report of the NINCDS-ADRDA Work Group under the auspices of Department of Health and Human Services Task Force on Alzheimer's disease. Neurology 34:939-944

24. Tanskanen A, Taipale H, Koponen M, Tolppanen AM, Hartikainen S, Ahonen R, Tiihonen J (2015) From prescription drug purchases to drug use periods - a second generation method (PRE2DUP). BMC Med Inform Decis Mak 15:21

25. Tanskanen A, Taipale H, Koponen M, Tolppanen AM, Hartikainen S, Ahonen R, Tiihonen J (2017) Drug exposure in register-based research - an expert-opinion based evaluation of methods. PLoS One 12:e0184070

26. Taipale H, Tanskanen A, Koponen M, Tolppanen A-M, Tiihonen J, Hartikainen S (2016) Agreement between PRE2DUP register data modeling method and comprehensive drug use interview among older persons. Clin Epidemiol 8:363-371

27. Herings RMC, Stricker BHC, De Boer A, Bakker A, Sturmans F, Stergachis A (1996) Current use of thiazide diuretics and prevention of femur fractures. J Clin Epidemiol 49:115-119

28. Bokrantz T, Ljungman C, Kahan T, Boström KB, Hasselström J, Hjerpe P, Mellström D, Schiöler L, Manhem K (2017) Thiazide diuretics and the risk of osteoporotic fractures in hypertensive patients. Results from the Swedish Primary Care Cardiovascular Database. J Hypertens 35:188-197

29. Butt DA, Mamdani M, Austin PC, Tu K, Gomes T, Glazier RH (2013) The risk of falls on initiation of antihypertensive drugs in the elderly. Osteoporos Int 24:2649-2657

30. de Vries M, Seppala LJ, Daams JG, van de Glind EMM, Masud T, van der Velde N (2018) Fall-risk-increasing drugs: a systematic review and meta-analysis: I. Cardiovascular drugs. J Am Med Dir Assoc 19: 371.e1-371.e9. https://doi.org/10.1016/j.jamda.2017.12.013

31. Dharmarajan TS, Dharmarajan L (2015) Tolerability of antihypertensive medications in older adults. Drugs Aging 32:773-796

32. LaCroix AZ, Ott SM, Ichikawa L, Scholes D, Barlow WE (2000) Low-dose hydrochlorothiazide and preservation of bone mineral density in older adults. Ann Intern Med 133:516-526

33. Reid IR, Ames RW, Orr-Walker BJ, Clearwater JM, Horne AM, Evans MC, Murray MAF, McNeil AR, Gamble GD (2000) Hydrochlorothiazide reduces loss of cortical bone in normal postmenopausal women: a randomized controlled trial. Am J Med 109: $362-370$

34. Sund R, Nurmi-Lüthje I, Lüthje P, Tanninen S, Narinen A, Keskimäki I (2007) Comparing properties of audit data and routinely collected register data in case of performance assessment of hip fracture treatment in Finland. Methods Inf Med 46:558-566

35. Forsman J, Taipale H, Masterman T, Tiihonen J, Tanskanen A (2018) Comparison of dispensed medications and forensictoxicological findings to assess pharmacotherapy in the Swedish population 2006 to 2013. Pharmacoepidemiol Drug Saf 27:11121122

36. Greenland S, Thomas DC (1982) On the need for the rare disease assumption in case-control studies. Am J Epidemiol 116:547-553

Publisher's note Springer Nature remains neutral with regard to jurisdictional claims in published maps and institutional affiliations. 